\title{
KEUNGGULAN KOMPARATIF BAMBU SEBAGAI BAHAN ALTERNATIF PENGGANTI BAHAN BAKU UNTUK KELOMPOK INDUSTRI KERAJINAN DI WONOREJO PASURUAN
}

\author{
Arum Dwi Dayanti ${ }^{13}$, Ulul Abror ${ }^{2}$, \\ ${ }^{1,2)}$ Program Studi Manajemen, Universitas Narotama Surabaya \\ ${ }^{1)}$ E-Mail: arumdwidayanti@gmail.com \\ ${ }^{2)}$ E-Mail: abrorrulul11@gmail.com
}

\begin{abstract}
Managing the viability of small businesses in small industry groups requires carefulness and special ability, especially when the business actor faces the scarcity of raw materials used in the production process. As the researchers face in the survey on the parcel craftsmen group, which used to use rattan material has now switched to using bamboo materials in maintaining the continuity of production in the region Wonorejo Pasuruan. Parcel craftsmen groups in this area until now amounted to 33 craftsmen who have largely switched to using bamboo materials as the main ingredient of making the parcel. With the use of bamboo materials that are easier in the business can be maintained well maintained.
\end{abstract}

\section{Keywords: alternative materials, material scarcity, small business actors}

Abstrak. Mengelola kelayakan usaha kecil dalam kelompok industri kecil membutuhkan ketelitian dan kemampuan khusus, terutama ketika pelaku bisnis menghadapi kelangkaan bahan baku yang digunakan dalam proses produksi. Seperti yang peneliti hadapi dalam survei pada kelompok pengrajin parcel, yang dulu menggunakan bahan rotan kini telah beralih menggunakan bahan bambu dalam menjaga kelangsungan produksi di wilayah Pasuruan Wonorejo. Kelompok pengrajin parcel di daerah ini hingga kini berjumlah 33 pengrajin yang sudah beralih ke sebagian besar menggunakan bahan bambu sebagai bahan utama pembuatan bungkusan itu. Dengan penggunaan bahan baku yang lebih mudah dalam bisnis dapat terpelihara dengan baik.

Kata kunci: bahan alternatif, kelangkaan bahan, pelaku usaha kecil

\section{PENDAHULUAN}

Bagi pengrajin bambu adalah berkah tersendiri ketika dihadapkan pada saat-saat tertentu di mana tempat pesanan untuk kontainer atau paket paket meningkat secara dramatis, misalnya menjelang Idul Fitri, Natal, Tahun Baru dan momen-momen tertentu lainnya. Ketika bambu tidak umum digunakan, sebagian besar pengrajin masih bertahan untuk membuat tempat parcel rotan, tetapi karena komoditas rotan semakin dilindungi oleh pemerintah dalam ekosistemnya dan menghindari terjadinya perusakan hutan dan kepunahan maka secara perlahan pengrajin di mana bungkusan beralih ke bahan bambu untuk mempertahankan kelangsungan hidup bisnis. Di sisi lain, material bambu jauh lebih berlimpah daripada pasokan bahan rotan yang sudah menipis dan terancam punah. Aktor usaha kecil dalam hal pengadaan bahan mentah sangat penting untuk kegiatan bisnis seharihari mereka dan pengadaan bahan baku sangat terkait dengan arus kas, karena pengadaan bahan baku tergantung pada seberapa banyak pendanaan usaha kecil untuk memenuhi kebutuhan bahan baku.

Berdasarkan Peraturan Menteri Kehutanan nomor P.35 / Menhut-II / 2007 tentang hasil hutan bukan kayu, penggunaan bahan rotan telah diatur sedemikian rupa untuk melestarikan produk jangka panjang komoditas hutan, sehingga perlu mengubah sikap dan persepsi pelaku usaha kecil untuk mulai menggunakan bahan alternatif di tempat proses produksi. Menurut 
Artaya (2008), penting bagi pelaku usaha untuk mengubah sikap dan mulai mengalihkan bahan baku rotan ke bahan baku alternatif untuk mendukung kelancaran proses pelaku usaha kecil agar tidak terkendala dalam jangka panjang, sementara dalam studi yang berbeda Artaya (2018) kegiatan proses produksi, menipisnya sumber bahan baku primer merupakan kendala umum bagi sebagian besar usaha kecil, tetapi pelaku usaha kecil dituntut untuk jeli dan kreatif untuk mengubah desain fisik produk agar menjadi mampu menggunakan bahan baku alternatif yang memiliki keunggulan komparatif dari titik nilai ekonomi. Dengan menggunakan bahan baku bambu untuk proses pembuatan parcel place, maka harga jual parcel menjadi lebih murah dibandingkan jika parcel itu dibuat dengan bahan baku rotan. Kondisi ini membuat tempat bungkusan bambu memiliki keunggulan komparatif dibandingkan dengan bungkusan yang terbuat dari rotan

\section{KAJIAN TEORI}

\section{Keunggulan Komparatif}

Teori keunggulan komparatif adalah teori yang diusulkan oleh Irlandia (2013) yang memiliki arti sebagaimana dijelaskan oleh Irlandia bahwa keunggulan komparatif akan tercapai jika suatu negara mampu memproduksi lebih banyak barang dan jasa dengan biaya lebih rendah daripada negara lain.

Dalam teori keunggulan komparatif, suatu bangsa dapat meningkatkan standar hidup dan pendapatannya jika ia mengkhususkan diri dalam produksi barang atau jasa yang memiliki produktivitas dan efisiensi tinggi. Misalnya, Indonesia dan Malaysia memproduksi kopi dan timah. Indonesia mampu menghasilkan kopi secara efisien dan dengan biaya rendah, tetapi tidak dapat memproduksi timah secara efisien dan murah.

Sebaliknya, Malaysia mampu menghasilkan timah secara efisien dan dengan biaya rendah tetapi tidak dapat menghasilkan kopi secara efisien dan murah. Dengan demikian, Indonesia memiliki keunggulan komparatif dalam memproduksi kopi dan Malaysia memiliki keunggulan komparatif dalam memproduksi timah. Perdagangan akan saling menguntungkan jika kedua negara bersedia menukar kopi dan timah.

\section{Kelemahan Komoditi Rotan Alam}

Saputra (2011) mengatakan bahwa saat ini bisnis rotan Indonesia menghadapi kondisi serius, ada tiga kendala utama:

1. Volume dan nilai ekspor produk rotan menurun terus. Para pengusaha mebel rotan dan pengusaha kerajinan dituduh, yang kesemuanya diakibatkan oleh kekurangan bahan baku dan kekurangan pasokan. Sehingga rotan tidak lagi andal sebagai bahan baku dalam proses produksi produk kerajinan tangan.

2. Produksi rotan mentah terus menurun, karena petani pengumpul rotan kecewa karena pendapatan dari bisnis ini tidak dapat lagi menyediakan mata pencaharian mereka. Para pengusaha rotan menduga bahwa kelebihan pasokan telah terjadi bahwa harga jatuh dan para petani enggan mencoba di bidang rotan alam lagi.

3. Hal ini tidak dan tidak disadari oleh pengusaha komoditas rotan alam, yaitu munculnya produk subtitusi rotan imitasi plastik yang mulai mengambil alih fungsi rotan alam. Namun sayangnya nilai ekonomi plastik rotan imitasi masih kalah dibandingkan komoditas bambu untuk industri kerajinan di Indonesia.

Dalam retrospeksi, kondisi yang mengkhawatirkan ini adalah hasil dari kebijakan pemerintah yang tidak layak. Kebijakannya adalah menutup dan membuka keran ekspor rotan atau rotan setengah jadi tanpa menyertakan pertimbangan dan analisis yang komprehensif. Seolah-olah dengan mengatur pasokan bahan baku, seluruh industri rotan alam dapat dikendalikan sesuai keinginan. Mengingat bahwa semua kegiatan bisnis dengan industri skala kecil atau industri rumahan membutuhkan kepastian tentang pasokan bahan baku utama dalam jangka panjang. 
Sedangkan nilai pasokan suatu komoditas bahan, terkadang masih di bawah regulasi yang ditentukan oleh pemerintah dalam penggunaannya untuk kehidupan dunia industri kecil di negara tersebut.

\section{Keunggulan Bambu Untuk Industri Handicraft}

Menurut penjelasan Malamassam (2012) Dalam proses penggunaan sehari-hari untuk industri kerajinan, ternyata bambu memiliki banyak keunggulan dibanding komoditas nonkayu, keunggulan ini antara lain:

1. Bambu mudah ditanam dan tidak memerlukan perawatan khusus. Untuk melakukan penanaman bambu, tidak diperlukan investasi besar, begitu tanaman sudah stabil, hasilnya bisa diperoleh terus tanpa tanam lagi. Budidaya bambu dapat dilakukan hanya tentang siapa saja, dengan peralatan sederhana dan tidak memerlukan penyediaan pengetahuan yang tinggi.

2. Dalam masa pertumbuhan, bambu tertentu dapat tumbuh secara vertikal $5 \mathrm{~cm}$ per jam, atau $120 \mathrm{~cm}$ per hari. Bambu dapat digunakan dalam banyak cara. Berbeda dengan pohon kayu hutan baru yang siap dipanen dengan kualitas yang baik setelah usia 40-50 tahun, maka bambu dengan kualitas baik dapat diperoleh pada usia 3-5 tahun.

3. Tanaman bambu memiliki ketahanan yang luar biasa. Rumpun bambu yang telah terbakar, masih bisa tumbuh lagi, bahkan ketika Hiroshima dibom dengan bom atom ke tanah, bambu adalah satu-satunya jenis tanaman yang dapat bertahan hidup.

4. Bambu memiliki kekuatan yang cukup tinggi, kekuatan tarik dapat bersaing dengan baja. Namun, kekuatan bambu yang tinggi tidak dimanfaatkan dengan baik karena biasanya struktur bambu batang dipasangkan dengan pasak atau tali dengan kekuatan rendah.

5. Pipa berbentuk bambu sehingga momen kelembabannya tinggi, oleh karena itu bambu cukup baik untuk menahan momen lentur. Ditambah dengan sifat bambu elastis, struktur bambu memiliki ketahanan yang tinggi baik terhadap angin dan gempa bumi.

Berdasarkan beberapa keunggulan karakter bambu di atas, maka ketika bambu digunakan sebagai kerajinan bahan baku akan memiliki nilai ekonomi yang tidak kalah dari kerajinan yang terbuat dari produk rotan alam. Sejak 2009, komoditas bambu telah menjadi populer sebagai bahan baku produk kerajinan tangan untuk menggantikan bahan baku rotan. Industri mebel dan industri kerajinan mulai beralih secara intensif ke bahan baku bambu dan penggunaannya semakin meluas, terutama proses produksi kerajinan tangan dan produk rumah tangga lainnya. Bahkan untuk pangsa pasar produk ekspor, bahan baku bambu dianggap sebagai alternatif yang lebih ramah lingkungan oleh pelanggan luar negeri, kondisi ini membuat industri kerajinan di negara tersebut lebih kredibel dalam mengembangkan berbagai desain produk kerajinan yang memprioritaskan bahan baku komoditas bambu.

\section{Nilai Ekonomi Dari Bambu}

Seperti yang dijelaskan oleh Nayla (2014) Dari segi bambu ekonomis sangat menguntungkan, sehingga bambu yang ditanam tumbuh menjadi rumpun, maka rumpun bambu akan berfungsi sebagai bank. Kapanpun diperlukan, batang bambu dapat ditebang sama seperti orang yang tertarik pada deposito. Selain itu, bahkan jika semua rumpun ditebang, rumpun baru bisa tumbuh lagi. Ini artinya setelah menanam bambu, hasilnya bisa diambil terus menerus. Permintaan bambu di Indonesia semakin meningkat. Jika orang-orang biasa memakai bambu karena mereka tidak mampu membelinya, kini sedikit demi sedikit bambu telah beralih ke barang-barang seni yang dibeli karena keindahannya.

Peralatan rumah tangga seperti meja, kursi, dipan, bambu bulkheads telah memasuki hotel bintang dan bangunan, bangunan wisata. Lebih dari itu, perabotan rumah dari bambu juga mulai menjadi komoditas ekspor. Pengrajin bambu sudah mulai merasa kesulitan membeli bambu dengan usia yang cukup, karena budidaya bambu di Indonesia masih sangat langka. Budidaya ini hanya ditemukan di beberapa daerah, antara lain di Bengkulu dan Lampung. 


\section{Citra Produk Kerajinan Bambu}

Dari sudut pandang penilaian dan persepsi konsumen, ternyata produk yang dibuat dari kerajinan bambu memiliki respon yang sangat baik dari pelanggan. Hal ini ditandai dengan meningkatnya permintaan untuk produk kerajinan yang terbuat dari bambu, tidak termasuk produk kerajinan untuk parsel. Sebaliknya, produk kerajinan yang terbuat dari rotan semakin menurun permintaannya. Ada beberapa dampak positif dari penggunaan bahan bambu untuk produk kerajinan, antara lain (Artaya et al, 2018):

1. Bahan bambu mampu menyerap panas sehingga lebih ramah lingkungan, terutama jika bambu digunakan sebagai produk kerajinan tangan atau kebutuhan rumah tangga. Jadi dampak ruangan terasa dan terasa lebih sejuk dan keren.

2. Bambu memiliki struktur yang lebih lentur dan lentur sehingga tidak mudah pecah dan memiliki kandungan air lebih tinggi daripada bahan rotan, sehingga kondisi ini lebih menguntungkan jika bambu digunakan sebagai bahan untuk mebuat berbagai jenis produk kerajinan.

3. Bambu memiliki karakter khusus dan mampu mengurangi berbagai jenis bakteri karena mampu mengeluarkan ion positif dari dalam batang. Dengan kandungan serat yang lebih tinggi, bahan bambu cenderung lebih sesuai dalam fungsinya sebagai produk kerajinan (peralatan) rumah tangga dan kantor.

4. Bahan bambu tidak berbau meski sudah lama digunakan, karena material bambu lebih padat dari pada bahan rotan. Tentunya kondisi ini mampu memberikan daya tahan lebih lama dibandingkan bahan rotan.

\section{METODE PENELITIAN}

\section{Lokasi Penelitian}

Lokasi adalah sekelompok pengrajin handycraft menggunakan bambu sebagai bahan baku alternatif. Di sini ada sekitar 12 pengrajin rumah tangga yang masih aktif berproduksi, di Desa Wonorejo Pasuruan.

\section{Sampel Penelitian}

Secara keseluruhan, jumlah pengrajin yang dijadikan sampel dalam penelitian ini ada sebanyak 12 pengrajin, dengan berbagai bentuk produk andalan mereka, yang semuanya terbuat dari bambu.

\section{Data Penelitian}

Data diperoleh melalui serangkaian wawancara dengan pengrajin pakaian tradisional, untuk mencari tahu beberapa poin penting yang berhubungan dengan produksi pakaian dalam upaya untuk meningkatkan penjualan mereka. Sehingga data yang didapat data primer di bentuk dengan ukuran skala numerik.

\section{Model Analisis Data}

Untuk menetapkan keputusan dalam penelitian, maka alat analisis yang pen eliti gunakan yaitu analisis korelasi adalah untuk mengetahui apakah ada hubungan antara penggunaan bahan baku bambu alternatif dengan peningkatan nilai penjualan produk handycraft tersebut. Analisis model regresi berganda digunakan (Sugiyono, 2010).

\section{Kerangka Dasar Pemikiran}

Berikut ini disajikan gambar-gambar yang akan memberikan kejelasan pemikiran tentang upaya meningkatkan penjualan melalui penggunaan bahan baku alternatif bambu. 


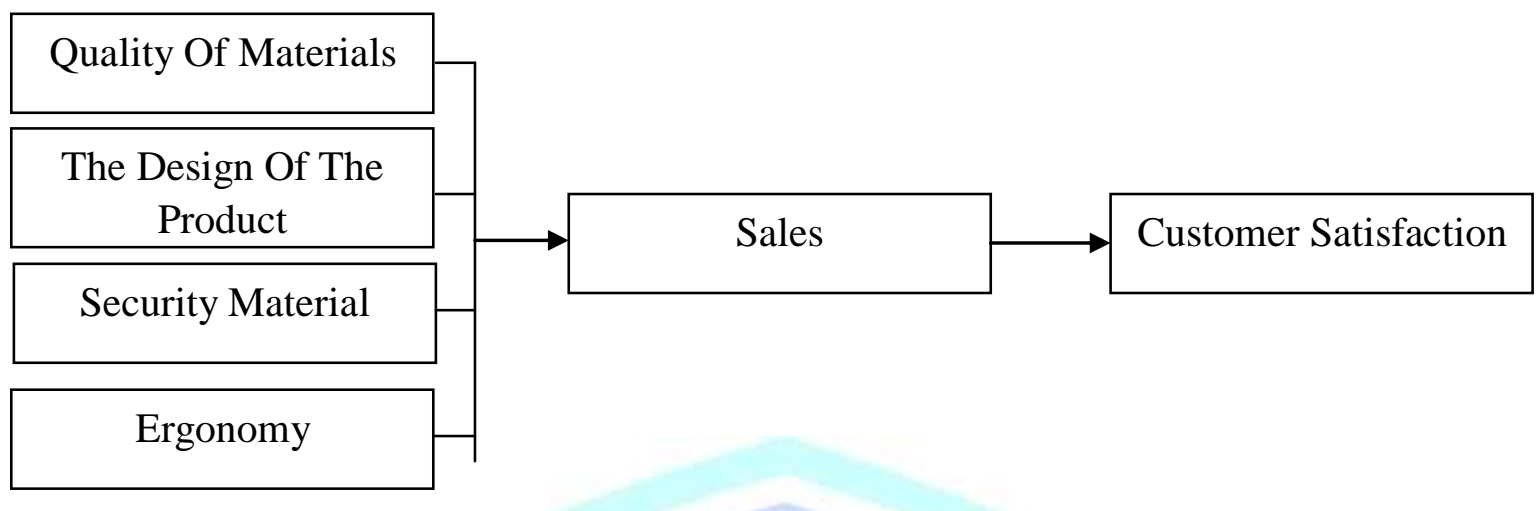

Gambar 1. Hubungan Antara Penggunaan Bahan Alternatif Dengan Penjualan Produk
yang Bermuara Pada Tingkat Kepuasan Konsumen

Sumber : Restu, Muhhamad. 2012, Kekayaan Hutan Sulawesi Yang Tergerus, Penerbit: P3i Press, Ujung Pandang

\section{HASIL DAN PEMBAHASAN}

Berdasarkan hasil wawancara di lapangan, peneliti mengumpulkan data menggambarkan bahwa konsumen jauh lebih menyukai penggunaan bahan baku alternatif dibandingkan dengan penggunaan bahan baku bambu bukan bambu. Di sini para peneliti menunjukkan hasil bidang pengumpulan data:

\section{Tabel 1. Analisis regresi hasil}

Sumber: hasil analisis.

\begin{tabular}{|c|c|c|c|c|c|c|}
\hline \multicolumn{7}{|c|}{ Correlations } \\
\hline & & Product sales & $\begin{array}{l}\text { Material } \\
\text { quality }\end{array}$ & $\begin{array}{l}\text { Product } \\
\text { design }\end{array}$ & Material safety & Ergonomy \\
\hline \multirow[t]{3}{*}{ Product sales } & Pearson Correlation & 1 & $.840^{x x}$ & $.588^{x}$ & .530 &,- 186 \\
\hline & Sig. (2-tailed) & & 001 &, 044 & .076 &, 562 \\
\hline & $N$ & 12 & 12 & 12 & 12 & 12 \\
\hline \multirow[t]{3}{*}{ Material quality } & Pearson Correlation & $.840^{x x}$ & 1 & .420 & .454 &,- 380 \\
\hline & Sig. (2-tailed) & ,001 & & .174 & .138 & .223 \\
\hline & $N$ & 12 & 12 & 12 & 12 & 12 \\
\hline \multirow[t]{3}{*}{ Product design } & Pearson Correlation & $.588^{x}$ & .420 & 1 & .233 & -.133 \\
\hline & Sig. (2-tailed) & .044 & .174 & & .466 & .680 \\
\hline & $N$ & 12 & 12 & 12 & 12 & 12 \\
\hline \multirow[t]{3}{*}{ Material safety } & Pearson Correlation & .530 & .454 & .233 & 1 & .182 \\
\hline & Sig. (2-tailed) & .076 & .138 &, 466 & & .571 \\
\hline & $N$ & 12 & 12 & 12 & 12 & 12 \\
\hline \multirow[t]{3}{*}{ Ergonomy } & Pearson Correlation &,- 186 &,- 380 &,- 133 & .182 & 1 \\
\hline & Sig. (2-tailed) & .562 & .223 &, 680 & .571 & \\
\hline & $N$ & 12 & 12 & 12 & 12 & 12 \\
\hline
\end{tabular}

*. Correlation is significant at the 0.01 level (2-tailed)

*. Correlation is significant at the 0.05 level (2-tailed)

hodel Summary

\begin{tabular}{|c|l|r|r|r|}
\hline Model & $\mathrm{R}$ & $\mathrm{R}$ Square & $\begin{array}{c}\text { Adjusted } \mathrm{R} \\
\text { Square }\end{array}$ & $\begin{array}{c}\text { Std. Error of } \\
\text { the Estimate }\end{array}$ \\
\hline 1 & $.896^{a}$ & .803 & .690 & .400 \\
\hline
\end{tabular}

a. Predictors: (Constant), Ergonomy, Product design, Material safety, material quality

b. Dependent Variable: Product sales 
ANOVA ${ }^{\mathrm{b}}$

\begin{tabular}{|ll|r|r|r|r|r|}
\hline Model & \multicolumn{1}{c|}{$\begin{array}{c}\text { Sum of } \\
\text { Squares }\end{array}$} & df & Mean Square & F & Sig. \\
\hline 1 & Regression & 4,548 & 4 & 1,137 & 7,113 &, $013^{a}$ \\
& Residual & 1,119 & 7 &, 160 & & \\
& Total & 5,667 & 11 & & & \\
\hline
\end{tabular}

a. Predictors: (Constant), Ergonomy, Product design, Material safety, Material quality

b. Dependent Variable: Product sales

Coefficients $^{a}$

\begin{tabular}{|c|c|c|c|c|c|c|}
\hline \multirow{2}{*}{\multicolumn{2}{|c|}{ Model }} & \multicolumn{2}{|c|}{ Unstandardized Coefficients } & \multirow{2}{*}{$\begin{array}{c}\text { Standardized } \\
\text { Coefficients }\end{array}$} & \multirow[b]{2}{*}{$\mathrm{t}$} & \multirow[b]{2}{*}{ Sig. } \\
\hline & & $B$ & Std. Error & & & \\
\hline \multirow[t]{5}{*}{1} & (Constant) & $-1,233$ & 1,243 & &,- 992 &, 354 \\
\hline & Material quality &, 833 & 279 & .700 & 2,990 &, 020 \\
\hline & Product design & .276 &, 185 & .276 & 1,489 &, 180 \\
\hline & Material safety &, 094 &, 151 &, 131 & .625 &, 552 \\
\hline & Ergonomy &, 084 & 182 &, 093 & 461 &, 659 \\
\hline
\end{tabular}

a. Dependent Variable: Product sales

Charts

Histogram

Dependent Variable: Product sales

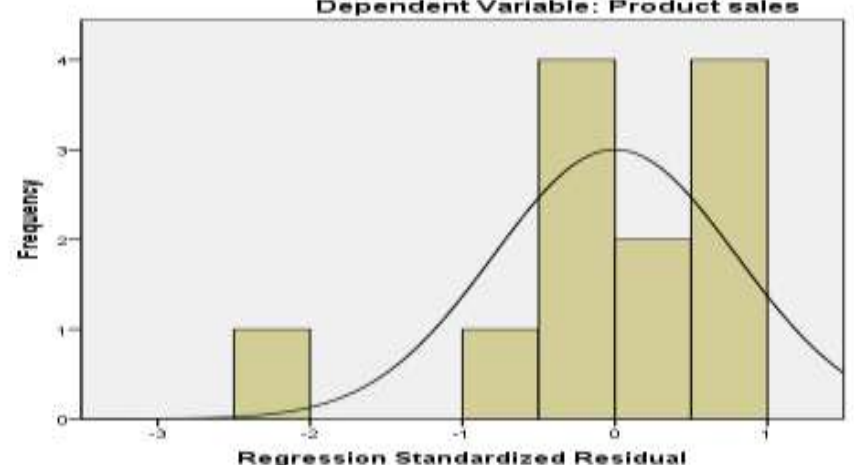

Mian $=3,958-45$

-

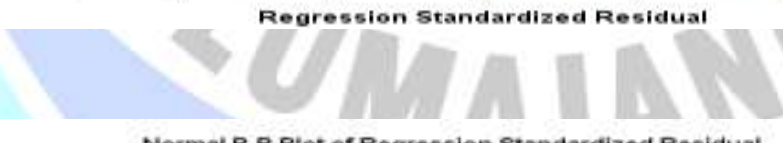

Normal P.P Plot of Regression Standardized Residual

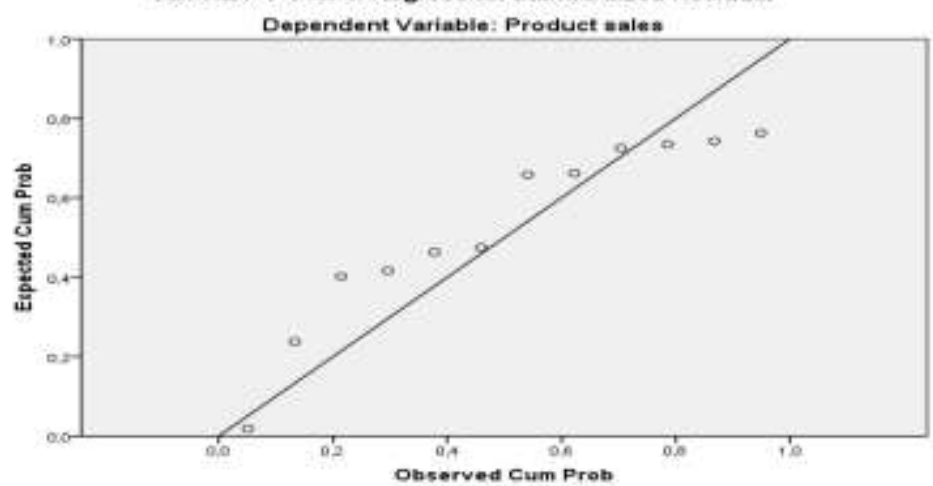




\section{Pembahasan}

Dari hasil analisis di atas untuk melihat bahwa hasil analisis korelasi menunjukkan ada dua komponen dalam proses penggunaan bambu sebagai bahan baku alternatif dalam peningkatan penjualan yang memiliki hubungan linier yaitu, kualitas bahan dan desain produk ini. berarti kedua komponen ini berperan dalam meningkatkan penjualan pada kelompok industri pakaian di Wonorejo Pasuruan. Artinya untuk meningkatkan aktivitas penjualan dalam bentuk pemilihan material, kualitas dan desain produk menjadi konstituen utama dalam kegiatan ini.

\section{PENUTUP}

\section{Simpulan}

Dari uraian dan penjelasan di atas, pada bagian akhir artikel ini kami dapat menjelaskan tentang kesimpulan yang dapat kami sampaikan sebagai berikut:

1. Bambu dalam hal penggunaannya sebagai produk kerajinan bahan baku memiliki nilai ekonomi yang sama dibandingkan dengan komoditas rotan. Tetapi komoditas bambu tidak terancam dengan kelangkaan karena selain mudah untuk ditanami, bambu adalah tanaman yang dapat ditemukan hampir di semua wilayah atau dataran, berbeda dengan rotan yang cenderung terkonsentrasi di kawasan kehutanan.

2. Semakin lama tingkat permintaan untuk bahan bambu untuk industri kerajinan lebih tinggi karena bambu telah dapat diterima oleh konsumen sebagai salah satu dari berbagai bahan alternatif yang memanfaatkan pembuatan berbagai produk untuk memenuhi kebutuhan hidup manusia, terutama produk kerajinan kayu.

3. Bambu memiliki nilai ekonomi yang cukup tinggi dalam perekonomian, terutama yang terkait dengan proses produksi yang membutuhkan alternatif pengganti bahan baku dalam jangka panjang dan mampu mengatasi kelangkaan bahan baku industri kerajinan.

4. Dalam berbagai penggunaan dan manfaat, bambu memiliki nilai tambah yang cukup diterima oleh konsumen dalam upaya menghasilkan berbagai bentuk produk dengan memanfaatkan komoditas alam yang jauh lebih murah dan mampu meningkatkan efisiensi penggunaan bahan baku untuk industri kerajinan tangan.

\section{Saran}

Untuk mendukung industri kerajinan tangan dan proses produksi industri kecil baik di perkotaan maupun pedesaan yang memanfaatkan bahan bambu sebagai alternatif pengganti rotan, ada beberapa saran yang perlu menjadi fokus perhatian yaitu:

1. Pemerintah lebih membudayakan penggunaan bambu dalam memanfaatkan sumber bahan baku alternatif untuk industri kerajinan non kayu di masa depan melalui budidaya yang didukung oleh peraturan untuk menguntungkan pelaku usaha yang memiliki kepentingan dalam industri kerajinan tangan atau kerajinan.

2. Pemerintah harus melakukan pembinaan terhadap berbagai jenis industri kerajinan yang menggunakan bambu sebagai bahan baku utama dalam proses produksinya, sehingga kelangkaan rotan dapat diatasi dengan munculnya bambu sebagai bahan alternatif untuk industri kecil.

3. Penggunaan bambu akan dapat menghindari kerusakan hutan karena eksploitasi hasil alam atau hutan yang terlalu berlebihan, sehingga program ini akan dapat melestarikan hutan dengan lebih baik. Karena jika eksploitasi hasil hutan dalam bentuk rotan jika tidak dikendalikan dengan baik akan dapat merusak ekosistem hutan, karena rotan merupakan salah satu komoditas hasil hutan yang harus dilindungi dan penggunaannya lebih bijak, terutama terkait dengan kegiatan kerajinan tangan. industri.

\section{DAFTAR RUJUKAN}

Artaya, I Putu. 2018, Pengaruh Sikap Dan Keyakinan Konsumen Dalam Keputusan Pembelian Tepung Terigu Merek Gunung Bromo Produk PT. Bogasari Flour Mils Surabaya, Jurnal Bisma (Bisnis dan Manajemen), Unesha 1 (1). 
Artaya, I Putu. 2018, Dasar-Dasar Manajemen Operasi dan Produksi, Narotama University Press, Surabaya.

Artaya, I Putu., Kamisutara, M., Baktiono, RA., 2018, Pengaruh Citra Produk Berdasarkan Analisis Persepsi Konsumen Pada Kelompok Usaha Aneka Pangan Di Sidoarjo, E-Jurnal Tata Sejuta STIA Mataram, Vol. 4, No. 1.

Ireland. (2013). The Management of Strategy: Concept and Cases (10th ed.) International Edition. Penerbit: Cengange Learning, Canada.

Malamassam, Daud. 2012, Membedah Potensi Hutan, Penerbit: IPB Press, Bogor.

Nayla, Aktifa P. 2014, Tembus Pasar Ekspor Kerajinan dan Makanan, Penerbit: Laksana, Jakarta.

Peraturan Menteri Kehutanan. Nomor : P.35/Menhut-II/2007, Tentang Hasil Hutan Bukan Kayu, 28 Agustus 2007, (http : // ifcc-ksk.org / documents / documents / regulation /P35_2007_HASIL_HUTAN_BUKAN_KAYU.pdf).

Restu, Muhhamad. 2012, Kekayaan Hutan Sulawesi Yang Tergerus, Penerbit: P3i Press, Ujung Pandang.

Saputra, Denny. 2011, Membedah Kondisi Industri Rotan Indonesia, 23 Februari 2011, (\{ HYPERLINK "http://dennysaputra085248088848.blogspot.co.id/2011/02/membedahkondisi-industri-rotan.html" \}).

Sugiyono, 2010, Statistik Untuk Penelitian, Penerbit Alfabeta, Jakarta

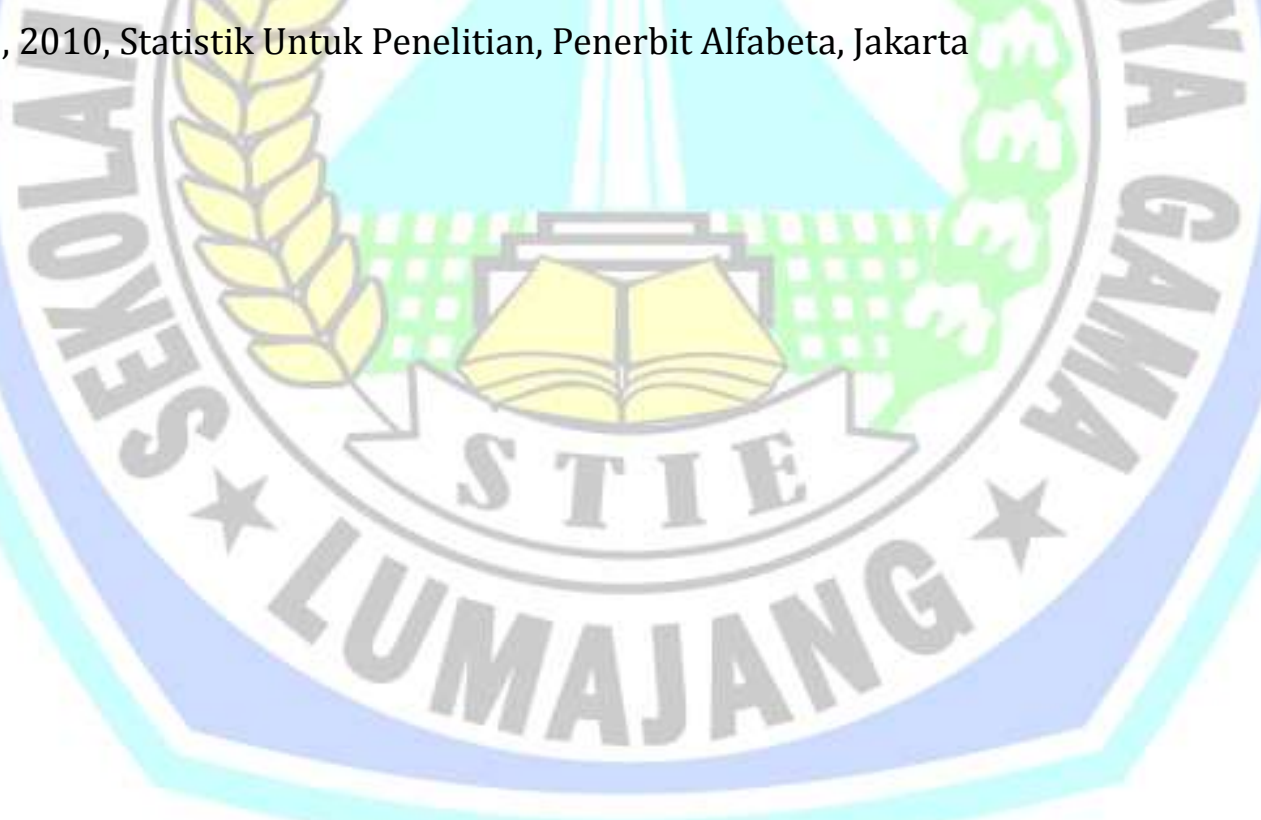

